
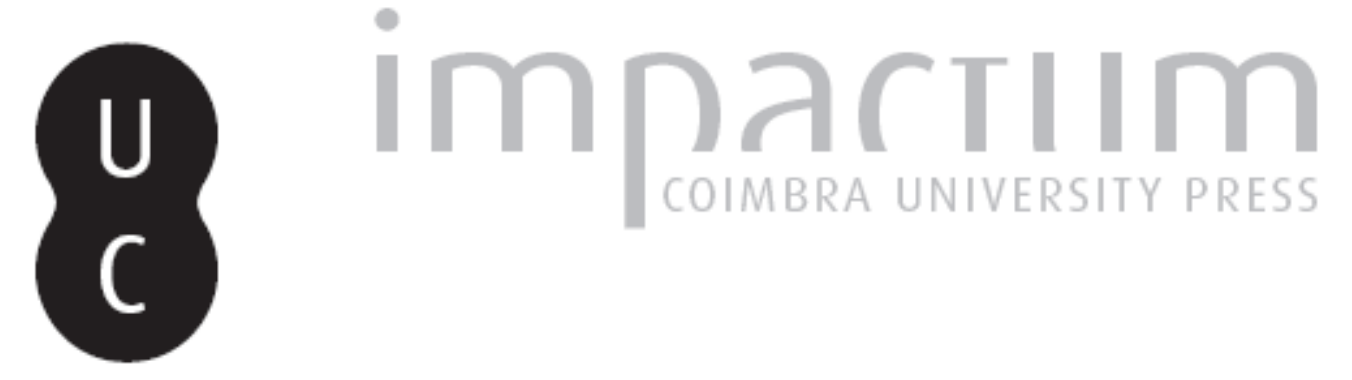

\title{
Vicissitudes de uma glória
}

\author{
Autor(es): Rocha, Andrée
}

Publicado por: Imprensa da Universidade de Coimbra

URL persistente:

URI:http://hdl.handle.net/10316.2/43920

DOI:

DOI:https://doi.org/10.14195/2183-8925_4-2_17

Accessed : $\quad$ 26-Apr-2023 06:09:32

A navegação consulta e descarregamento dos títulos inseridos nas Bibliotecas Digitais UC Digitalis, UC Pombalina e UC Impactum, pressupõem a aceitação plena e sem reservas dos Termos e Condições de Uso destas Bibliotecas Digitais, disponíveis em https://digitalis.uc.pt/pt-pt/termos.

Conforme exposto nos referidos Termos e Condições de Uso, o descarregamento de títulos de acesso restrito requer uma licença válida de autorização devendo o utilizador aceder ao(s) documento(s) a partir de um endereço de IP da instituição detentora da supramencionada licença.

Ao utilizador é apenas permitido o descarregamento para uso pessoal, pelo que o emprego do(s) título(s) descarregado(s) para outro fim, designadamente comercial, carece de autorização do respetivo autor ou editor da obra.

Na medida em que todas as obras da UC Digitalis se encontram protegidas pelo Código do Direito de Autor e Direitos Conexos e demais legislação aplicável, toda a cópia, parcial ou total, deste documento, nos casos em que é legalmente admitida, deverá conter ou fazer-se acompanhar por este aviso.

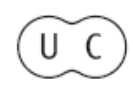




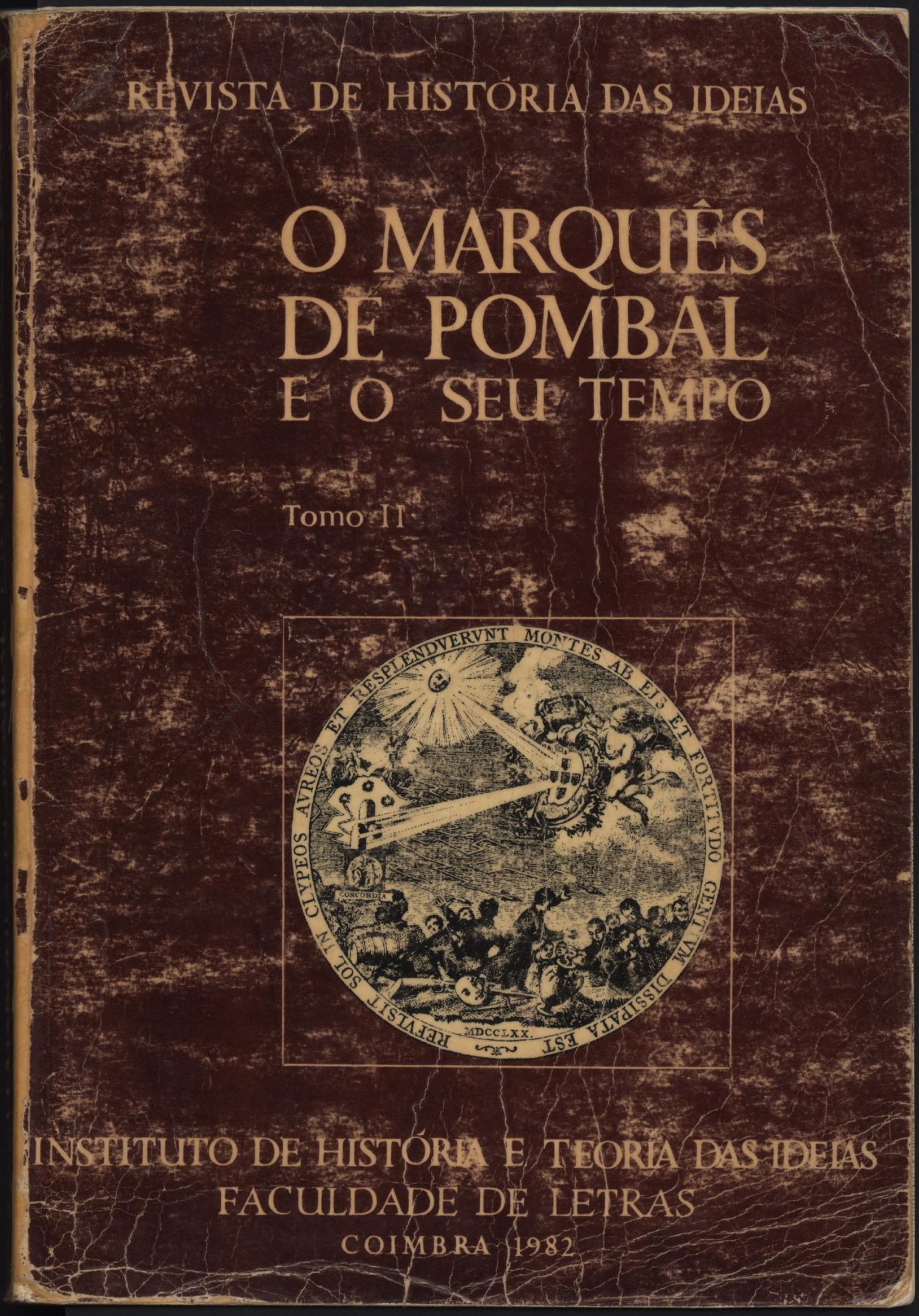




\section{ANDREE ROCHA *}

\section{VICISSITUDES DE UMA GLÓRIA}

E, por si só, um assunto fascinante observar o nascimento, as vicissitudes e o ressurgimento periódico da glória de certas figuras políticas. Esta oscilação nem sempre se processa ao compasso dos polos convencionais das efemérides, nem, sobretudo, em relação à totalidade da personagem celebrada. Ao fazer (por imperativo de calendário ou em demanda de garantes do passado que possam justificar o presente) o balanço duma existência humana relevante, cada época ajusta esse perfil às variantes da mentalidade reinante, extraindo dele as ilações que mais lhe convêm.

Equacionado em termos de expressão literária, o problema adquire uma coloração peculiar, que implica - além do posicionamento concreto dos escritores em relação ao poder vigente ou, a mais longo prazo, da perspectiva histórica em voga - , uma íntima ligação com normas, formas e funções da literatura. Mais complexa se torna a avaliação de juízos quando a figura em foco é o detentor dum mando absolutista, com facetas positivas e outras execráveis, como é o caso do Marquês de Pombal. 0 pragmatismo materialista e tecnocrata do estadista, fazendo tábua râsa de opiniões discordantes e pouco atreito a tomar em consideração as liberdades fundamentais do homem e muito menos as dos criadores, em todo o tempo tidos como mais subversivos, não pode deixar de provocar uma bipolarização na maneira como os seus contemporâneos o julgaram. No decorrer dos tempos, essa bipolarização continua; mas assenta em coordenadas diferentes, pois o que era válido e o que era condenável para uma época não o é necessariamente para a outra.

(*) Faculdade de Letras da Universidade de Coimbra. 
Ora, nesse plano restrito, a literatura setecentista fornece-nos alguns dados curiosos, mesmo se, por vezes, contraditórios. Como é natural, um abismo separa os que foram atingidos, directa ou indirectamente, pelas prepotências do Marquês, e os que receberam ou esperaram dele benesses e protecção.

No auge do seu prestígio, mal se conceberia, no entanto, uma oposição declarada e nominal. Se Alexandre de Gusmão passa da prudente cortesia patente na missiva que dirige a Pombal em 1742 ( $\left.^{1}\right)$ a uma desaprovação radical, só a exprime em cartas particulares a terceiros que pensam como ele, e, mesmo assim, tendo a cautela de mencionar o visado sob o nome de código de "o Soldão", e os seus acólitos mais chegados sob o de "os seus três vizires», socorrendo-se dum disfarce exótico frequente no século XVIII, e cujas conotações são facilmente decifráveis. Por sua vez, uma das vítimas mais ilustres da repressão pombalina, a Marquesa de Alorna, evita sobranceiramente referir o perseguidor da sua família e, quando o faz, é mediante a sarcástica alcunha de "o marido", sendo "a mulher», obviamente, o rei D. José I... Finalmente, é do seu exílio de Baiona que o oratoriano Teodoro de Almeida, o newtoniano autor da Recreação Filosófica, comenta, esperançoso, os progressos da hemiplegia que vitimou o monarca, atento às repercussões doutra natureza que o facto possa vir a ter no destino do seu todo poderoso ministro.

Inversamente, instituições como a Arcádia Lusitana depositaram no político grandes esperanças, que têm, como moeda de troca, diversas composiçōes de circunstância, individuais, é certo, porque assinadas, mas globalmente inseridas nos pressupostos doutrinários daquela colectividade. $\mathrm{E}$ se, a breve trecho, essas esperanças foram goradas, mercê da íntima ligação dos árcades com o Oratório, que Pombal passou a considerar com suspicácia, não é menos verdade que alguns de entre eles se mantiveram fiéis à sua admiração inicial.

Exemplo disso é Cruz e Silva, que tece ao político os mais rasgados elogios nas suas Odes Pindáricas. Neste volume, Elpino Nonacriense enaltece - em moldes literários extre mamente medíocres, diga-se desde já - uma longa série de personagens históricas, desde Vasco da Gama ao Conde de Schaumburg-Lippe. Sebastião José tem as honras das Odes XXV, XXVI, XXVII e XXVIII, e o seu primogénito, Henrique José Maria de Carvalho, alçado por afinidade a um nível que

(') Alexandre de Gusmão, Cartas, Imprensa Nacional, 1981, 
nada nada justifica, é celebrado num epitalâmio que engloba transparentemente o seu progenitor. Por causa dos santos adoram-se as pedras...

Nas três primeiras odes mencionadas, Cruz e Silva gaba o "grão Marquês» por ter introduzido a indústria em Portugal, desterrado a preguiça, e reconstruído Lisboa, «em suas cinzas sepultada». Ainda se refere às actividades diplomáticas de Pombal em Londres e Viena de Áustria, à fundação de Santo António de Arenilha (Vila Real de Santo António) e aos primeiros passos dados para rasgar "a densa treva" que reinava em Coimbra, focando assim as principais facetas da actuação do dinâmico estadista. Nem uma palavra, mesmo velada, sobre o seu despotismo, as confiscações de bens, as prisões, e até medidas insólitas como a de mandar salgar as terras dos Távoras. A ode, como género optimista, não se compadece com ninharias destas...

A Ode XXVIII, essa, é inteiramente consagrada à Reforma da Universidade. Na sequência de alusões anteriores do poeta, e numa figura muito ao gosto do Iluminismo, essa composição constrói-se sobre a antítese trevas/luz. Coimbra será, doravante, um paradigma de saber e de razão

Pois de Pombal a clara e fausta estrela Com seus raios a cobre e faz mais bela Rasgando o negro véu com que a cobria A ignorância fea...

A sã filosofia, que até ali "só e sem culto, esquálida jazia», verá finalmente "roxear a aurora». Já se pisa sem medo a estrada da verdade, dá-se instrução ao povo, vê-se raiar, graças ao reformador,

Da ciência a luz brilhante...

Num espírito crítico como o do autor do Hissope, que soube estigmatizar com picante ironia defeitos de moda e de classe, tal ditirambo não pode ser imputado apenas ao pendor arcádico para um poetar louvaminheiro e de circunstância. E certamente motivado, também, por uma sincera admiração perante a determinação e a eficiência dum homem disposto a enfrentar energicamente carências ou catástrofes nacionais. Quanto à reforma dos estudos universitários, o escritor, antigo estudante de Direito em Coimbra, estava em condições de apreciar ao seu justo valor o alcance das propostas pombalinas. 0 teor do seu discurso poético e o relevo dado ao assunto provam bem que aderia a um projecto aberto e mo- 
derno. Além disso, essa admiração não se desvanece com os anos. Quando, já magistrado no Brasil, escreve o soneto Sobre a queda do Rio Tieté, que simboliza para ele

O próprio retrato dum poderoso, Pois quanto mais sublime é seu estado Mais estrondosa é sua ruína...

não é descabido pensar-se que teria ainda em mente o prestigioso ministro. Só que a antiga admiração se matizava agora de melancolia, ao reflectir sobre o destino dos grandes deste mundo.

Grandeza, aliás, amplamente contestada por aqueles que, acima do planeamento da Nação, punham os direitos do Homem, o que se revela através de abundante produção panfletária, de cariz não-literário, ou encontra eco em obras de estrangeiros, no dealbar da Revolução francesa $\left({ }^{2}\right)$. Anos mais tarde, a perspeztiva tornará a mudar, quando Garrett, na sua comédia A Sobrinha do Marquês, e no prefácio que a antecede, faz de Pombal uma vítima das camadas sociais que ajudou a emancipar e a progredir, aplicando uma situação passada ao momento histórico então vivido (1848). Entretanto, assistimos à valorização parcial de certos comportamentos do ministro, na medida em que o reinado seguinte, além de coarctar igualmente a liberdade, estagnava ou retrocedia em muitos nontos. Lá diz o povo: "Atrás de mim virá quem bom me fará!»!

Este pormenor verifica-se até zom as Odes Pindáricas. Certamente lidas por ocasião de sessões arcádicas, nunca foram publicadas em vida do autor. E quando aparecem, em 1801, na Imprensa da Universidade, mais do que uma homenagem póstuma ao discutível valor literário de tais textos, podemos descortinar na publicação um tributo à figura que neles ocupava maior espaço.

Confirma esta hipótese a edicão de mais obras setecentistas tiradas do esquecimento ou do anonimato nas primeiras décadas do século seguinte, nomeadamente as que se relasionam com a reforma universitária.

Com efeito. o «sol da Razão" que bafejara a vetusta instituição fora, infelizmente, de pouca dura. Desaparecido Pom-

$\left(^{2}\right)$ P. ex. o romance americano Adventures of Alonso: containing some striking anecdotes of the present Prime Minister in Portugal, publicado em Londres em 1775, segundn informa Maria Leonor Machado de Sousa, em artigo a sair no próximo volume de Biblos. 
bal da cena política, sucessivos despachos reais vieram alterar, num sentido repressivo e retrógrado, as conquistas renovadoras, demonstrando-se assim a fragilidade de toda a semente progressista num solo que não foi suficientemente amanhado para a receber. E esse aspecto particular, mas importantíssimo, da "viradeira" deixava atónitos e indignados os que tinham aderido à modernização. Mesmo que esta não abrangesse, na perpectiva de hoje, modificações radicais no domínio da especulação filosófica, já se mostrara relevante no plano científico, em que fora cuidadosamente acompanhada das estruturas indispensáveis à sua concretização (observatório, teatro anatómico, jardim botânico, laboratórios, etc.). Mas as esferas passadistas, hostis a um progresso tido como subversivo, não tardariam em miná-la, fazendo voltar as coisas à sua primitiva forma.

Daí os numerosos pasquins de escolares de Coimbra, desgostosos por verem o "sábio plano» do Marquês já vacilante, ou claramente destruído.

Um dos mais conseguidos é, sem dúvida, O Reino da Estupidez, que correu por largos anos anónimo e manuscrito. Sátira mordaz a diversos aspectos da sociedade portuguesa, transforma-se, nos dois últimos cantos, numa chacota feroz a mestres e autoridades da Universidade coimbrã. Inscreve-se na linha de represália verbal que encontraremos mais tarde nos escritos de Garrett, Antero, Eça, Teófilo Braga, António Nobre e António Feijó, todos eles estudantes de Coimbra, e concordes em estigmatizar, como o poeta romântico, a estultície dos «sabichōes do Mondego" e os entraves postos pela instituição ao livre desabrochar dos espíritos juvenis.

Não sendo Francisco de Melo Franco, autor do Reino da Estupidez, comparável com esses grandes nomes da literatura, a sua obra merece, no entanto, alguma atenção.

Inconformista duramente castigado pela Inquisição a pretexto de opiniōes heterodoxas, no tempo em que cursava Medicina, não é, quando escreve $O$ Reino da Estupidez, um mero escolar facecioso, redigindo um panfleto sem consequências. Trata-se dum homem lido, que cita a propósito o Lutrin de Boileau, a Hissopaida de Cruz e Silva, e cujo texto dá claros indícios de ter conhecido a Dunciad de Alexander Pope $\left({ }^{3}\right)$. No decorrer da narração, ainda intercalará, na fala

( $\left.{ }^{3}\right)$ Esta leitura é confirmada pela menção explícita do texto inglês na versão do poema que se encontrava nos papéis de Fr. Alexandre da Sagrada Família e comporta 8 cantos em vez de 4 . 
de uma das suas personagens, um curioso excurso em que são chamados a capítulo D. Quixote, Dulcineia e Mambrino.

A insersão da obra no género herói-cómico, de que o autor sabe os preceitos, coaduna-se perfeitamente com o propósito de confrontar duas mentalidades em conflito: cómica será a vertente crítica que envolve uma delas, heróica, a que alinha com o defensor da justa razão. 0 certo é que possui inegável graça, que as personagens são capazmente caricaturadas ou delineadas, e que a ironia (por vezes transformada em humor negro) atinge o seu alvo: incomodar a facção conservadora, vítima do libelo, e despertar o interesse do público para um tema sempre candente. Na verdade, o escrito motivou diversas réplicas, circularam dele numerosas cópias manuscritas (mais de vinte, recolhidas nas bibliotecas principais do país) e, depois da 1.a edição em Paris (1818), a popularidade do texto está atestada por sucessivas reedições durante os cinquenta anos seguintes. Mais do que as ferroadas à Justiça, a práticas supersticiosas fomentadas pelo clero e ao fausto desmedido dos prelados, é provável que fosse a sátira ao descalabro post-pombalino dos estudos universitários que suscitava semelhante aceitação. E curioso notar, a este propósito, que no Parnaso Lusitano, organizado por Garrett ( ${ }^{4}$ ) e publicado em 1827, a composição fica reduzida aos dois últimos cantos - precisamente os que dizem respeito a Coimbra - com o título reajustado de a $A$ Estupidez Triunfante em Coimbra. Como já observámos em relação às Gdes Pindáricas, é possível que tal selecção tivesse a ver com o recrudescimento do apreço votado à reforma de Pombal.

Mas voltemos ao texto, na perspectiva que aqui nos interessa. Os dois primeiros cantos só aludem de raspão ao célebre estadista. Assim. no episódio do velho que não obtém justiça dum magistrado manietado pela força da fidalguia, a vítima lastima, suspirando, a falta de Pombal,

Pois ele era somente quem sabia

Desta raça abater o grande orgulho...

(4) Incumbido pela casa Aillaud de organizar um florilégio da poesia portuguesa, Garrett renegou mais tarde a inclusão de certas composiçōes, como se depreende duma nota ao Bosquejo, repetida no opúsculo Da Educação. Antes de ficar completa a impressão, e tendo-se o poeta ausentado de Paris, «um homem por nome Fonseca, a quem da minha algibeira paguei para rever as provas, tomou a liberdade de alterar tudo, introduzindo na colecção produções ridículas de gente desconhecida». Sempre atento à conjuntura, o Divino sacudia a água do capote. Contudo, a presença dum manuscrito de O Reino da Estupidez nos papéis do seu tio e mentor intelectual leva a pensar que a inclusão teria partido dele. 
Pelo contrário, os cantos III e IV, que narram a chegada a Coimbra da deusa Estupidez e a sua solene entronização no pátio da Universidade, ao referir, de modo escarninho, a indigência mental da reaç̧ão, mais não faz do que sublinhar a dimensão da Reforma e do seu promotor.

E simples a fábula utilizada: o Reitor da Universidade convoca o Conselho doutoral para saber se a instituição deve ou não receber a Estupidez, de que a vinda está anunciada. A maioria dos docentes pronuncia-se a favor duma recepção triunfal, e acabam por restituir à deusa tutelar o seu trono, fortemente abalado pela Reforma pombalina.

Claro que esta alegoria é pretexto para satirizar o obscurantismo em relação a novas ciências e novos métodos pedagógicos decorrentes destas, bem como as figuras da hierarquia universitária que o protagonizam. Alguns dos visados são nomeados (Bustoque, Bezerra, Trigoso, etc.); outros são facilmente identificáveis. Trata-se, pois, duma sátira de feição pessoal, o que não impede que se estenda a uma análise de costumes. Com efeito, as diversas categorias de docentes não são apenas caracterizadas pela sua relutância em aceitar novos rumo pedagógicos. A esta está associada uma série de comportamentos que condizem com a sua indigência mental. Condenam, como Beócios, a geometria, a medicina experimental, a botânica e zoologia aplicadas, por frívolas ou por contrárias à fé. Mas são, além disso, vaidosos, dorminhocos, comilōes, mulherengos, interesseiros, bajuladores e oportunistas. 0 próprio Reitor, tíbio e timorato, mesmo em assuntos da sua regedoria, chega ao extremo de pedir conselho ao criado de quarto, que o tira de apuros indicando-lhe o modo de proceder.

Contra a opinião geral, só uma voz discrepante: a de Tirceu, que defende corajosamente o agrande invicto, o imortal Carvalho»,

\section{qual sol brilhante \\ De escura noute dissipando as trevas.}

Com uma combatividade que não exclui nem teme o martírio, rebate a posição maioritária, faz apelo à consciência de cada um, e reprova o oportunismo dos que, na altura da visita de Pombal à Universidade, lhe fizeram mil vénias, e põem agora de rastos tudo o que de novo se fez.

A diatribe não surte o mínimo efeito, uma vez que a assembleia se escuda em formalismos obsoletos e preconceitos clericais, escandalosamente desajustados em relação à mo- 
dernidade da Reforma: nada toca no cerne o que é, por natureza, retrógrado e rotineiro.

O mais curioso é que, neste libelo, os estudantes também não são poupados. Em toda a Academia, haverá dez que mereçam esse nome. Os outros jogam, bebem, desencaminham moças, e aceitam com o maior regozijo o regresso da padroeira, que lhes proporcionará numerosos feriados. Por analogia com o que se passa com os lentes, esse estado de inércia ou mesmo de indisciplina estudantil, que o autor verbera no presente, constitui também o regresso a uma situação anterior, à qual o Marquês tentara pôr cobro. Melo Franco não alude explicitamente às medidas impeditivas de regalias arbitrárias (perdão de acto, dispensa de matrícula, admissão à Universidade sem preparação conveniente, etc.) que constam dos Estatutos e tinham plena razão de ser, uma vez que a população escolar era maioritariamente constituída por jovens de estirpe nobre, que entendiam estar acima das normas comuns. Mas como levaram o mesmo caminho que as inovações científicas, o panorama negativo destina-se, obviamente, a estabelecer um contraste com os breves anos em que a Reforma funcionou em pleno.

Mais uma vez se notará, a este propósito, como a perspectiva pode mudar, em função de outros pressupostos. Cem anos depois de $O$ Reino da Estupidez, Fialho de Almeida fazia, num texto preambular de $A$ Esquina, as mais severas restrições a Pombal, por ter instaurado o «foro privado». Claro que o passo em que insiste nesse aspecto é obra de um jornalista que, numa óptica libertária, não era capaz de colocar a questão em termos diacrónicos. Aliás, é possível que Fialho, ao apelidar de "grilhão absolutista» essas regras disciplinadoras, fizesse confusão com medidas posteriores à morte do estadista, essas sim de devassa pura e simples em matéria de actos, opiniões e leituras.

Ainda convirá mencionar outro texto, a Ode de Filinto Elísio, datada de Paris, 4 de Julho de 1806, e incluída nas suas Obras. Nela o autor rememora, em dia aniversário, o momento em que «clérigos tristes», depois de lhe ralarem a paciência (a expressão é dele) «com perguntas, com cárceres, com tratos», o levaram ao exílio. Recorda em dado passo uma conversa havida entre ele e mais dois proscritos, Avelar Brotero e Ribeiro Sanches, em que este último reprova a existência de «assassinos tonsurados» que perseguem os estudiosos e «ao saber põem mordaças», e apela para novo Hércules que limpe essa «cavalhariça» 
Das profícuas ciências,

vingando assim Anastácio da Cunha, Bartolomeu Lourenço (o inventor da "passarola voadora»), Filinto Elísio e o próprio Sanches, de cujo génio a pátria ficou privada porque a queriam manter "na boçal ignorância». 0 relevo dado a pessoas ligadas quer à mentalização que precedeu a Reforma pombalina, quer a representantes do magistério progressista (e entre eles, também, Avelar Brotero, certamente omitido por esquecimento), quer à investigação aplicada, quer ainda à poesia, e os termos iluministas em que tal discurso é formulado, permitem ver na mencionada Ode mais um protesto contra a reacção post-pombalina, e, por conseguinte, mais um louvor implícito àquele que, pelo contrário, estimulara o saber e desejara erguer Portugal, nesse e noutros domínios, ao nível das outras nações. Se Pombal não é concretamente mencionado nesse texto, é que os ventos prenunciadores do liberalismo que sopravam pela Europa e até pela América do Norte não se coadunavam com a feição despótica do regime por ele instaurado. Assim, obliterava-se a grandeza do estadista responsável por uma indubitável viragem intelectual, enquanto se repetiam com fervor os tópicos fundamentais do iluminismo que o inspirou. Mais perto de nós, o fenómeno seria invertido quando, durante a ditadura salazarista, se aceitaria plenamente o governo autoritário do Marquês, olhando severamente as medidas por ele tomadas no sentido de enfraquecer o poder da Igreja ou de certas ordens religiosas, e considerando com cautelosas reservas os escritores que participaram do espírito esclarecido.

Tão certo é que, mesmo por esta reduzida amostra, se não deve esperar da História juízos globais e definitivos. Ela exproba, omite ou magnifica, condicionada por uma infinidade de factores variáveis, que vão desde as ideologias, às crenças e às modas literárias. 0 exemplo de Pombal é significativo. A sua glória estará sempre à mercê desses fogos cruzados. 